\title{
Avaliação de tutores e facilitadores sobre o processo de formação de facilitadores de Educação Permanente em Saúde no município de Londrina, Paraná
}

\author{
Evaluation of tutors and facilitators on the formation process \\ of facilitators on Permanent Health Education of Londrina, Paraná
}

Fernanda de Freitas $M$ endonça ${ }^{1}$

Elisabete de Fátima Pólo de Almeida $\mathrm{N}$ unes ${ }^{2}$

M ara Lúcia Garanhani ${ }^{3}$

Alberto Durán González ${ }^{2}$

${ }^{1}$ Departamento de Enfermagem, Faculdade Integrado de Campo M ourão. Rodovia BR 158, KM 207. 87300-970 Campo M ourão PR. fernandafreitasmendonca@ yahoo.com.br

${ }^{2}$ Departamento deSaúde Coletiva, Centro de Ciências da Saúde,

Universidade Estadual de Londrina.

${ }^{3}$ Departamento de Enfermagem, Centro de Ciências da Saúde, Universidade Estadual de Londrina.
Abstract The M inistry of $\mathrm{H}$ ealth has instituted the Permanent $\mathrm{H}$ ealth Education (PHE) with the purpose to change both the practices and the education of health professionals. As a strengthening strategy of this policy, the formation of PHE tutors and facilitators has begun in the whole country. This project aims to analyze this individuals' perception on the PHE facilitator course in Londrina, PR. It is a qualitative study, carried out with PHE tutors and facilitators from December 2006 to January 2007. Data were collected through semi-structured interviews and submitted to the discourse analysis proposed by $M$ artins and Bicudo. By analyzing two categories the study revealed: Contributions from the permanent health education course and Critics on the facilitators' formation process. Theresults showed that despite some limitations such as the course period, selection of facilitatorsand difficulties with the course methodology, the education of facilitators has brought contributions to the systematical knowledge on PHE and the opportunity to reflect upon the practices in health.

Key words Health policy, Health education, Human resources in health
Resumo A formação de tutores e facilitadores iniciou-se como estratégia de fortalecimento da política deEducação Permanenteem Saúde(EPS). 0 objetivo deste estudo foi analisar as percepções desses sujeitos sobre o curso defacilitadores deEPS em Londrina (PR). Trata-se de um estudo qualitativo, realizado com tutores efacilitadores deEPS, no período de dezembro de 2006 a janeiro de 2007. Os dados foram col etados por meio de entrevistas semiestruturadas e submetidos à análise de discurso proposta por M artins e Bicudo. Os resultados revelaram algumas críticas referentes ao processo de sel eção defacilitadores, tempo de duração e término do curso, dificuldades com a metodologia, entre outras. A pesar disso, os participantes salientaram contribuições, tais como a sistematização do conhecimento sobre EPS e a oportunidade de refletir sobre as práticas de trabalho. As críticas voltaram-se mais para aspectos operacionais, ao passo que as contribuições levantadas re feriram-se justamente aos objetivos centrais do processo de formação de facilitadores. Palavras-chave Política de Saúde, Educação em saúde, Gestão de pessoal em saúde 
Introdução

O M inistério da Saúde (MS) instituiu, em feve reiro de 2004, a política de Educação Permanente em Saúde (EPS), Portaria no 198/GM , como estratégia de transformação das práticas e da formação dos profissionais de saúde ${ }^{1,2}$.

A partir de então, houve em todo o país um processo de implantação de Pólos de Educação Permanente em Saúde (PEPS), enquanto instâncias colegiadas organizadas em locorregiões, que funcionam como parte do SUS, responsável pela mudança das políticas de saúde e das ações de educação na saúde ${ }^{3}$.

Uma vez garantido os espaços de discussão, tornou-se necessário qualificar os sujeitos do processo quanto ao entendimento sobre a EPS. Portanto, como estratégia de fortalecimento dessa política, o MS, em 2004, em parceria com a Escola Nacional de Saúde Pública (ENSP), iniciou a formação de tutores e facilitadores de EPS em todo o país4.

Houve dois momentos voltados para a formação de facilitadores de EPS. I nicialmente, um momento organizado pelo M S edirecionado para os polos e, posteriormente, outro com o auxílio do M S e da ENSP, mas de responsabilidade dos municípios colaboradores. A rededemunicípios colaboradores da EPS foi constituída com o objetivo de ampliar a capacidade de formulação, de ensino-aprendizagem, de desenvolvimento e de ação dos municípios.

No Paraná, a equipe da autarquia de saúde de Londrina, um dos municípios colaboradores, compreendeu einvestiu no potencial da EPS como ferramenta capaz de promover mudanças no processo de trabalho em saúde. Dessa forma, para promover a reorganização da assistência à saúde, fortalecer 0 acolhimento e a criação de vínculos, isto é, consolidar a implantação do Sistema Ú nico de Saúde (SUS), Londrina investiu na formação de aproximadamente 150 facilitadores de EPS para profissionais da rede básica, trabal hadores dos serviços de média e alta complexidade, serviços de apoio, instituições formadoras (estudantes e docentes) e representantes da comunidade ${ }^{5}$.

A formação de tutores e facilitadores de EPS foi uma iniciativa recente; logo, não se conhece como foram desenvolvidos esses processos, se o curso trouxe contribuições e quais foram as dificuldades vivenciadas por tutores e facilitadores durante o processo de formação. Diante dessas lacunas de conhecimento e dos obstáculos que permeiam a implementação da EPS, sobretudo, a reprodução das práticas hegemônicas, em que há a valorização de ações curativas, fragmentação e tecnificação da assistência ${ }^{6}$, torna-se relevante desvendar como se desenvolveu o curso de facilitadores de EPS.

Com base nisso, o objetivo deste estudo foi analisar as percepções de tutores e facilitadores sobre o curso de facilitadores de Educação Permanente em Saúde em Londrina (PR).

\section{Métodos}

Este estudo faz parte de uma dissertação de mestrado que foi financiada pelo Consel ho Nacional de Desenvolvimento Científico e Tecnológico (CN Pq). O estudo utiliza uma abordagem qualitativa quefavorecea exploração das experiências dos tutores e facilitadores de EPS. A pesquisa foi realizada em Londrina (PR), no período de dezembro de 2006 a janeiro de 2007, com nove tutores e dez facilitadores de EPS. Foram entrevistados os tutores do município formados pela ENSP/M S e os facilitadores que fizeram o curso desenvolvido pelo município de Londrina.

Como o número de tutores era pequeno (nove), todos foram entrevistados, enquanto 0 número de facilitadores foi determinado pela saturação das informações coletadas nas falas dos entrevistados, de modo que a inclusão de novos sujeitos não traria maior diversidade de informações.

Para identificar os tutores, foi utilizada a letra T; para os facilitadores, a letra F. As entrevistas em cada grupo foram numeradas e cada letra recebeu um número conforme a ordem da realização das mesmas. Assim, o último facilitador entrevistado recebeu o código F10.

Utilizou-se como instrumento de coleta de dados a entrevista semi estruturada pois, além de valorizar a presença do pesquisador, oferece todas as perspectivas possíveis para que o informante alcance a liberdade e a espontaneidade necessárias?.

A entrevista foi conduzida a partir de um roteiro, conten do questões sobre caracterização dos sujeitos do estudo e quatro questões referentes às percepções sobre o conceito de EPS, curso de facilitadores, necessidades eo papel do tutor edo facilitador. No intuito de aprimorar esse roteiro, realizou-se uma entrevista com um tutor e facilitador de EPS de outro município.

Este artigo analisa os discursos gerados a partir da questão: Qual a sua percepção sobre o processo de formação de facilitadores de EPS? 
Observando as recomendações de M inayo ${ }^{8}$ houvea preocupação de estabelecer um ambiente cordial, favorecendo uma comunicação clara e simples, com a finalidade de assegurar a compreensão dos tutores e facilitadores de EPS sobre os objetivos do estudo.

Antes do início das entrevistas, os participantes foram esclarecidos acerca do objetivo da pesquisa e de que seria utilizado gravador, na intenção de tornar mais rico o material coletado. Os tutores e facilitadores que concordaram em participar da pesquisa assinaram termo de consentimento livre eesclarecido.

As fitas foram transcritas na íntegra e de forma literal. Após as leituras, foram retirados os vícios de linguagem e feita a correção ortográfica para proteção dos participantes da pesquisa.

Para análise das entrevistas, foi utilizada análise de discurso proposta por $\mathrm{M}$ artins e Bicudo ${ }^{9}$, que abrange dois momentos. 0 primeiro momento consistiu na análise individual ou ideográfica. N este, foram realizadas leituras das descrições; em seguida, discriminadas as unidades de significado, que posteriormente foram interpretadas. 0 processo de interpretação contemplou as convergências das unidades de significados dentro do discurso de cada entrevistado. Em outras palavras, foram feitas junções daquilo que o sujeito repetia em seu discurso.

No segundo momento, foi feita a análise ge ral ou nomotética, que consistiu na compreensão e articulação dos diversos casos individuais como exemplos particulares em algo mais geral. N esta etapa, foi realizada a releitura das entrevistas, aproximação das unidades de significados individuais interpretadas e a identificação das convergências edivergências presentes. Esta aproximação possibilitou a construção de categorias que resultaram na estrutura do fenômeno estudado. Da análise, emergiram duas categorias: contribuições do curso de Educação Permanente em Saúde e críticas sobre o processo de formação de facilitadores.

Esse projeto foi autorizado pela Autarquia Municipal de Londrina e aprovado pelo Comitê deÉtica e Pesquisa da UEL.

\section{Resultadosediscussão}

Caracterização dos participantes do estudo

Dos dezenove participantes do estudo, dezesseis eram do sexo feminino e a idade dos entre vistados variou de 29 a 52 anos. Os sujeitos pertenciam a distintas categorias profissionais, destacando-se que todos os tutores possuiam formação superior, enquanto que a formação dos facilitadores variou do ensino fundamental ao nível superior (Tabela 1).

Os entrevistados trabal havam nos seguintes serviços de saúde: pronto atendimento, urgência e emergência, especialidades, atenção básica, instituição de ensino e no gerenciamento dos serviços de saúde em nível central.

\section{Críticas sobre o processo de formação} de facilitadores

0 processo de formação de facilitadores foi marcado por alguns percalços. Um tutor referiu que não se considerou a demanda do serviço durante a seleção dos facilitadores. Para ele, deveria haver maisfacilitadores nos locais em quea demanda do serviço fosse maior.

Feuerwerker ${ }^{10}$ relata que, em alguns municípios, existe um facilitador para cada equipe de saúde da família e que iniciativas como essas são muito importantes para disseminar e fortalecer a implementação local da política de EPS.

A pesar disso, o número reduzido de facilitadores em um serviço não deve servir de empeciIho para implementação da EPS, uma vez que é função do facilitador, assim como do tutor, mobilizar sujeitos para promover mudanças no ambiente detrabalho. Para tanto, éimprescindível que gestores estaduais e municipais façam parte desse processo e que, inclusive, ofereçam apoio político aos tutores e facilitadores ${ }^{11}$.

Osentrevistados criticaram o período no qual o curso foi realizado. Um tutor comentou que,

Tabela 1. Caracterização dos tutores e facilitadores de Educação Permanente em Saúde segundo a categoria profissional. Londrina (PR), 2007.

\begin{tabular}{lrcc}
\hline \multicolumn{1}{c}{ Categoria profissional } & \multicolumn{3}{c}{ Formação } \\
& Tutor & Facilitador & Total \\
\hline Agente comunitário de saúde & - & 01 & 01 \\
Auxiliar de enfermagem & - & 03 & 03 \\
Enfermagem & 04 & 03 & 07 \\
M edicina & 03 & 02 & 05 \\
Odontologia & 01 & 01 & 02 \\
Pedagogia & 01 & - & 01 \\
Total & 09 & 10 & 19 \\
\hline
\end{tabular}


em virtude da greve, no início do curso, muitas pessoas estavam desmotivadas, atémesmo aquelas mais comprometidas com o processo de trabalho. Após o término do curso, houve mais um processo de paralisação dos profissionais de saúde, fato que interrompeu a implementação das atividades relativas à EPS.

Se vocênão estiver em um momento favorável, édifícil quea EPS desencadeieoutros processos. (T6)

Deve-seconsiderar quea realidade não éalgo controlável; esses processos conflituosos, como greves, fazem parte do cotidiano dos trabalhadores e aprender a enfrentá-los é uma forma de ampliar a capacidade de análise sobre si mesmo, sobre os outros e sobre o contexto, aumentando, por consequência, a possibilidade deagir nestas situações ${ }^{12}$.

Embora um dos pressupostos da EPS seja discutir/refletir o processo de trabalho, a greve não foi um dispositivo de análise dos sujeitos envolvidos. I sso demonstra que os sujeitos ainda não haviam se constituído como grupo ativo e reflexivo que buscava entender e modificar sua realidade.

Um facilitador criticou a atuação dos tutores, pois não havia um trabalho articulado entre os mesmos e isso fez com que cada grupo fosse conduzido sem seconsiderar a essência do curso, que era produzir mudanças. Além disso, também afirmaram que os tutores não se reuniam e que não houve profundidade nas discussões.

Eu acho que a EPS, ela compreende várias fases. A primeira delas que é o ponto de partida éa sensibilização e predisposição a mudanças e essa primeira fase não aconteceu. (F4)

Por conta disso, o processo de formação foi considerado para al guns sujeitos apenas um curso: Eu imaginava que estaríamos todos nesse processo e com a mesma intensidade e no final, pra muito gente foi um curso. (T3)

As críticas referentes aos tutores podem estar relacionadas ao processo de formação de tutores, que, segundo eles, foi insuficiente, uma vez quenão trouxeacréscimo denovos conhecimentos e o período de formação foi escasso, incompatível com a complexidade dos conhecimentos que precisavam ser apropriados: Foi num final desemana, dois dias dereunião, eu acho quepoderia ter sido melhor. (T9)

Essa fala aponta para a possibilidade de alguns tutores não terem conseguido se apropriar de alguns conhecimentos acerca da EPS.

Segundo os participantes, falhas no processo de seleção de tutores contribuíram para a insegurança despertada em muitos deles. Oficialmen- te, a seleção dos tutores envolveu al guns critérios: o profissional deveria ocupar um cargo estratégico, ser articulado e/ou possuir alguma experiência prévia em educação permanente. Contudo, um participante afirmou que tais critérios não foram observados.

Sobre isso, Goulart ${ }^{13}$ afirma que há muitos questionamentos sobre a transparência do processo seletivo de tutores. 0 mesmo autor apontou que, em seu município, participou da tutoria uma pessoa distante da EPS em detrimento de pessoas ligadas ao processo de formação dos pólos. Também emergiram críticas sobre os facilitadores. 0 discurso a seguir expressa o conflito vivenciado por um tutor, cujo grupo não compreendeu o objetivo primordial do curso: mudança de prática: N ão consegui com meu próprio grupo. Percebi que não tinha acontecido mudança de prática. (T7)

A resistência dos facilitadores em acolher a proposta de trabalho da EPS fez com que este tutor optasse por distanciar-se do processo de EPS: Eu quero ficar longe de toda essa discussão para refletir, porque hoje eu acho que eu teria uma resposta baseada em toda a situação que nós vivemos. (T6)

Chama atenção nesse discurso o quanto as atitudes dos sujeitos envolvidos facilita ou dificulta 0 andamento do processo. As novidades despertam nos sujeitos duas atitudes: uma, de valorização, por suscitar nos profissionais a curiosidade de trilhar caminhos diferentes; outra, de rejeição, pelo medo do desconhecido ${ }^{10}$. No cotidiano do trabalho, os profissionais são constantemente submetidos a situações que Ihes exigem uma decisão. Nesse momento, é preciso não se assustar com o diferente, mas sim encarar o novo eproduzir as tecnologias eferramentas necessárias para lidar com os desafios que as novas formas de agir impõem ${ }^{10}$. Além de criar novas tecnologias, podem-se utilizar experiências anteriores sistematizadas e socializadas pelo curso para subsidiar decisões necessárias frente aos desafios do cotidiano do profissional de saúde.

Outra crítica, relatada por um tutor, refereseà participação incipienteno curso de representantes de alguns segmentos, tais como serviços denível terciário, instituições de ensino eusuários. Cabe aqui ressaltar que, quando se tem a intenção de real izar uma ação, é preciso considerar os tempos técnicos etempos políticos citados por Mário Testa. 0 tempo técnico é dependente de procedimentos, isto é, de tecnologias que precisam ser utilizadas para a realização de um plano. o tempo político é aquele necessário para que 
um plano idealizado seja compreendido pelos diferentes grupos sociais ${ }^{14}$. Assim, mesmo tendo as tecnologias necessárias para realização do curso de facilitadores, era preciso também considerar o tempo político, no intuito de obter mais aliados à implementação da política de EPS.

0 curso de facilitadoresutilizou a metodologia ativa na modalidade de ensino à distância (EAD). Sobreisso, os participantes referiram quefoi difícil se apropriar da metodologia do curso, uma vez que foram formados na pedagogia da transmissão: Então pra mim é novo, porque eu venho do ensino convencional, não aquele que você tem que correr atrás sozinho, então eu tive dificuldade (F7)

Eu sou uma pessoa que precisa de alguém me puxando, para mim é complicado, faz você perder um tempo. (F3)

0 estudo de $M$ oraes e $M$ anzani ${ }^{15}$ também revelou dificuldades presentes nos alunos de medicina ao se depararem com as metodologias ativas. N este estudo, os alunos afirmaram sentirem-se sozinhos no processo de aprendizagem.

As atitudes de estranhamento dos participantes acerca das metodologias ativas decorrem dea sua formação ter sido baseada em uma pedagogia passiva, não crítica, de pouca interação com o objeto de conhecimento e não valorização do conteúdo ${ }^{16,17}$. Segundo Freire ${ }^{18}$ e Campos $^{19}$, essa posição do sujeito provoca alienação, que o impede de construir uma consciência crítica da realidade e uma atitude de autonomia.

De acordo com Luckesi ${ }^{20}$, a metodologia ativa éuma concepção educativa que estimula processos de reflexão, nos quais o aluno tem uma postura ativa em relação ao seu aprendizado. 0 mesmo autor cita alguns aspectos que envolvem a metodologia ativa: (1) inserção do aluno numa situação de experiência; (2) reflexão por meio de problemas quesejam desafiantes; (3) disponibilização de informações que permitam aos alunos pesquisar e descobrir soluções; (4) incentivo a soluções provisórias, as quais devem ser discretamente ordenadas com o auxílio do professor e (5) garantia de oportunidade de colocar as soluções à prova.

Esses aspectos foram valorizados no curso de facilitadores, mas isto não garante que os sujeitos incorporem tal metodologia com facilidade, uma vez queéintenção dessetipo de metodologia produzir e se alimentar das dificuldades, pois elas se traduzem não em obstáculos, mas em problemas que são discutidos e superados, o que constitui o processo de ensino-aprendizagem ${ }^{21}$.

Os princípios da metodologia ativa buscam o desenvolvimento do aluno ativo, participativo, crítico ecorresponsável pelo seu aprendizado. Isto provoca a necessidade de reverem antigas e presentes concepções do processo ensino eaprendizagem, o queimplica o movimento de ida e volta às formas pelas quais aprendeu. Cada um segue seu tempo e seu espaço de abertura para novos conceitos e novas práticas ${ }^{22}$.

Os sujeitos relataram dificuldades relacionadas com o EAD e falta de habilidade de alguns participantes no uso do computador, bem como o atraso na disponibilização do ambientevirtual de aprendizagem.

O EAD é uma ferramenta de ensino, ou seja, uma estratégia de ensino que pode se adequar tanto à metodologia ativa quanto à tradicional. De acordo com Alves e Nova ${ }^{23}$, o EAD é uma modalidade de ensino-aprendizagem que se estabelece com o auxílio de suportes tecnológicos digitais e de rede. Corroboran do os achados dessa pesquisa, Alves e $\mathrm{Nova}^{23}$ afirmam que muitos alunos têm dificuldades com o EAD, seja pela inibição frenteà riqueza detecnologias oferecidas $\mathrm{e} /$ ou pela não satisfação de suas necessidades.

Foram salientadas pelos participantes algumas limitações do material de apoio utilizado duranteo curso de facilitadores. Dentreelas, teve destaque a complexidade da linguagem:

Eu achei complicado, o livro não era muito fácil de compreender. Acho que poderia ter sido mais fácil. (F6)

Deacordo com Kramer ${ }^{24}$, épreciso existir um diálogo entre o leitor e o texto. Para que esse diálogo se estabeleça, é necessário que seu conteúdo expresse o cotidiano do leitor, mas el e deve ir além desse cotidiano, fazendo-o pensar criticamente. U ma linguagem complexa, distante da realidade do leitor, pode de fato inviabilizar 0 diálogo que deve ocorrer entre eles; todavia, tal dificuldade relatada pelos participantes pode também estar relacionada a esse "ir além" do cotidiano. A construção do conhecimento devepartir da realidade e do cotidiano do sujeito, porém é preciso construir uma nova síntese que represente um conhecimento mais elaborado $0^{16,25}$. 0 mesmo se dá na interação com o material, sendo necessário superar a visão ingênua.

O material de apoio era composto por quatro unidades de aprendizagem: unidade integradora, unidade de análise do contexto da gestão e das práticas de saúde, unidade de práticas educativas no cotidiano do trabal ho em saúde e unidade de trabal ho erelações na produção do cuidado em saúde ${ }^{26}$. Os assuntos discutidos estavam relacionados ao cotidiano do trabal ho em saúde. No entanto, um tutor referiu que o material não for- 
neceu subsídios suficientes para desenvolver o trabalho em equipe. Vale ressaltar que, por mais importante que seja prezar pela qualidade do material, isso por si só não garante o desenvolvimento do trabalho em equipe, uma vez que para isso também é preciso o comprometimento dos membros de uma equipe de saúde.

0 atraso no término do curso foi criticado pelos participantes. Deacordo com eles, isso contribuiu para desmotivar os profissionais e aumentar o número de desistentes: N ós tivemos problemas como a demora, nós começamos o curso em setembro, era para acabar em fevereiro, nós acabamos em julho. Houve desmotivação de algumas pessoas, algumas desistiram! (T5)

0 encerramento do curso também foi criticado por um facilitador. Para ele, esse momento deveria propiciar uma discussão sobre todo o processo, permitir troca de experiências e compartilhar estratégias de enfretamento das dificuldades. No entanto, não foi isso que ocorreu.

Vale ressaltar que o surgimento de críticas era inevitável, considerando o período de limitações em que processo de formação de facilitadores foi realizado. Além da paralisação dos profissionais de saúde queocorreu no município, houve também uma interrupção do apoio político e financeiro do governo federal para as ações relativas a EPS. N este contexto, o município seexpôs ainda mais, tendo um papel fundamental nos resultados desse processo, os quais foram reconhecidos pelostutores efacilitadorese serão apresentados na categoria seguinte.

\section{Contribuições do curso}

$$
\text { de Educação Permanente em Saúde }
$$

O curso de facilitadores de educação permanente trouxe contribuições para os profissionais bem como para o serviço de saúde. Dentre as contribuições, destacou-se a sistematização dos conceitos deEPS.

Para Vasconcellos ${ }^{16}$, a sistematização do conhecimento é fundamental para compreender 0 objeto, sobretudo quando a sistematização aponta caminhos para que o aprendizado se traduza em uma ação concreta na realidade. Conforme Anastasiou ${ }^{27}$, é por meio da sistematização que ocorre a consolidação dos conceitos apreendidos; ademais, tais sistematizações devem ser concebidas como provisórias, uma vez que o ser humano está em constante processo de construção do conhecimento.

Um tutor salientou que a compreensão sobre a EPS permitiu que os profissionais percebessem a importância da política no processo de trabaIho e possi bilitou a visual ização de caminhos para desenvolvêla.

Feuerwerker ${ }^{10}$ revela que um dos principais desafios para a implementação da EPS é a incompreensão dos sujeitos acerca dessa política e acrescenta que a formação de tutores e facilitadores é uma importante estratégia para superar esse desafio.

Em relação ao método utilizado durante o curso, tutores e facilitadores enfatizaram a possibilidade de olhar para a própria prática de trabalho, problematizando-a por meio de atividades de ação-reflexão-ação: Perfeito! Porque a metodologia propõe a problematização, a aprendizagem significativa. Você tinha que ter um olhar sobre a prática, identificar como você realiza sua prática e a partir dessa reflexão você ia para os cadernos e teorizava. (T1)

No contexto das práticas edu cativas da formação em saúde, em que ainda prevalece a pedagogia da transmissão, o curso defacilitadores permitiu que elementos da pedagogia crítica, tais como reflexão e problematização, fossem reconhecidos pelos participantes do estudo como algo importantena prática detrabalho. A relação ação-reflexão-ação transformadora éo eixo básico deorientação do processo de problematização ${ }^{28}$. Seu principal objetivo é despertar uma consciência crítica no sujeito, de modo queele reconheça sua interação com o processo deconhecer etenha a capacidade de interpretar e questionar a realidade ${ }^{28,29}$.

A reflexão e a problematização, quando se dão no coletivo, desvelam elementosfundamentais para reorganizar a prática de trabalho ${ }^{10}$. Além disso, favorecem a escuta, práticas cuidadoras, conhecimentos engajados e abertura aos usuários4.

Ao se comprometerem com o processo de trabalho, os participantes afirmaram sentiremse mais seguros para dar continuidade às ações de planejamento e avaliação que já estavam sendo desenvolvidas: 0 curso trouxe a possibilidade de dar continuidade num processo que a gente já tinha começado antes! Q ue era de estar discutindo com as equipes o seu processo de trabal ho, a necessidade de planejar eavaliar as ações que as equipes estavam desenvolvendo. (T4)

Para Freire ${ }^{18}$, comprometer-se é ser capaz de agir e refletir, superar a visão ingênua, fatalista, conhecendo ereconhecendo a própria realidade. A essência do compromisso é a solidariedade, já que o compromisso não se reduz a gestos de falsa generosidade, tampouco a uma relação em que apenas uma das partes é beneficiada ${ }^{18}$. 0 compromisso revela a maneira de ser e pensar 
politicamente. Portanto, aqueles que se dizem neutros, na verdade têm medo de se comprometerem. Aqueles que insistem em assumir uma neutralidade impossível comprometem-se apenas consigo mesmo e em favor de seus próprios interesses ${ }^{25} .0$ compromisso [...] só existe no engajamento com a realidade [...] somenteassim o compromisso é verdadeiro. Ao experienciá-lo num ato que necessariamente é corajoso, decidido e consciente, os homens já não se dizem neutros. A neutralidade frente ao mundo [...] reflete apenas o medo que sentem de revelar o compromisso $0^{18}$.

Campos ${ }^{19}$ também afirma que inexistem sujeitos completamente destituídos ou excluídos. Todos em certo grau sofrem a ação de alguma instituição e, em consequência, forma-se, mesmo que discretamente, uma constel ação de princípios e valores.

Sobre o material de apoio, tutores e facilitadores afirmaram que seu diferencial foi o de estar articulado com a realidade do trabal hador de saúde, propiciando a reflexão e a autocrítica. No estudo de $\mathrm{Job}^{30}$, os facilitadores também destacaram a qualidade do material.

Para um sujeito sentir-se interessado em conhecer determinado objeto, ele deve identificarse com ele $e^{16,18,25}$. Para tanto, é preciso que tal objeto tenha relação com a realidade do mesmo. N esse sentido, percebe-se o quanto éimportante conhecer a realidade do outro. A reflexão sobrea realidade permite a superação da compreensão fatalista das situações, isto é, significa descobrir o papel da consciência e da subjetividade na história, significa reconhecer que esta é mutável e que não há neutralidades ${ }^{18}$.

0 fato de o material oportunizar a reflexão sobre o cotidiano do trabalho permitiu aos sujeitos envolvidos que desenvolvessem a crítica e a autocrítica sobre a realidade. No entanto, embora reconheçam a qualidade do material, um tutor relatou que o sucesso da aprendizagem depende da disposição do facilitador e da compreensão dos sujeitos envolvidos em assumirem a sua responsabilidade enquanto trabalhador da saúde.

Os participantes afirmaram que a participação no curso contribuiu para o crescimento pessoal e profissional, pois propiciou trocas de experiências e discussões sobre as relações e o processo de trabalho.

A discussão sobre as relações de trabalho, oportunizada pelo curso defacilitadores, expressou uma conquista, uma vez que tais discussões são escassas nos ambientes de trabalho. 0 estudo realizado por Cotta et al. ${ }^{31}$ com profissionais da atenção básica revelou ainda que, em propor- ções não muito altas, há problemas na relação interna entre equipes de saúde da família.

0 trabalho em saúde tem suas bases nas relações interpessoais ${ }^{32,33}$. As relações se estabelecem a cada instante, seja com o usuário do serviço ou entre os profissionais. Rejeitar essas relações e a subjetividade dos sujeitos, as quais são essenciais no trabalho em saúde, resulta em diversas complicações, dentre elas a substituição do sujeito pela máquina ${ }^{32}$.

M erhy ${ }^{34}$, referindo-se à utilização de máquinas na assistência à saúde, denomina-as de tecnologias duras. Segundo esse autor, três tipos de tecnologia permeiam o processo detrabalho. Além dastecnologias duras, existem as tecnologias leveduras, que seriam os conhecimentos técnicos ou saberes estruturados, e as tecnologias leves, que se referem às relações. Segundo este autor ${ }^{34}$, elas são essenciais para a produção de cuidados, vínculos, acolhimentos e responsabilizações.

Quando o processo de trabal ho utiliza predominantemente as tecnologias duras, o trabalhador não tem liberdadepara ser criativo, se relacionar, criar vínculo com o usuário, experimentar soluções para os problemas que aparecem; além disso, não interage enão insere o usuário no processo de produção de sua própria saúde ${ }^{32}$. Diante do exposto, a abertura à subjetividade durante a prática do trabalho em saúde, torna-se essencial, sobretudo porque compreendem-se melhor as necessidades de saúde presentes no sujeito ${ }^{32}$.

Para que os profissionais valorizem tanto a sua quanto a subjetividade do usuário, é necessário que se reconheça naquilo que faz e que ele serealize por meio do trabalho. No entanto, percebe-se um distanciamento do profissional em relação aos demais profissionais e em relação a sua própria prática. Desse modo, não há interação entre os sujeitos e a prática, isto é, perde-se a essência do trabalho em saúde ${ }^{32}$. A pouca valorização das relações pessoais na atenção à saúde deve se em grande medida à falta de formação específica voltada para a comunidade ${ }^{35}$.

Outra contribuição mencionada por tutores refere-se a uma visão mais ampliada do processo de trabalho. Os discursos a seguir revelam que os profissionais passaram a contextualizar, conhecer outras realidades de trabal ho e os problemas presentes em outros níveis de aten ção à saúde: Você passa a discutir as questões do processo de trabalho, a questão da gestão do problema como um todo. (T4)

Consegui entender um pouco maisa dificuldade de quem está na lida, o que el es esperam do meu setor. (T5) 
M orin ${ }^{36}$ afirma que é preciso sempre estabelecer relações entreo fenômeno eo contexto: “[...] a aptidão para contextualizar e integrar é uma qualidade fundamental da mente humana, que precisa ser desenvolvida, e não atrofiada". Roschke $^{37}$ apresenta a contextualização do processo educativo como sendo um dos elementosfundamentais daEPS, uma vez que, por meio dele, evita-se a real ização de ações isoladas.

A pesar disso, a sociedade privilegia a fragmentação do conhecimento, incentivando a redução do complexo ao simples e a decomposição ao invés da recomposição. Com isso, revelaseuma inadequação cada vez maior entrea construção fragmentada de saberes e a complexa e multidimensional realidade ${ }^{36}$.

Os efeitos dessa simplificação do conhecimento são expressos pela falsa manipulação e controle dos fenômeno ${ }^{38}$. Diante disso, énecessária uma nova forma de pensar que contextualize, que reconheça as incertezas, as indeterminações dosfenômenos eos limites do conhecimento, isto é, o pensamento complexo ${ }^{36}$.

0 contexto no qual se revelam as insuficiências e as carências do pensamento simplificador constitui o momento ideal para imposição do pensamento complexo $0^{38}$. $\mathrm{Na}$ saúde, faz se necessária uma educação para a complexidade, uma vez que conhecimentos isolados não dão conta de suprir as necessidades de saúde dos sujeitos ${ }^{38}$

Para os participantes, os resultados positivos do curso devem-se ao bom esclarecimento acerca do papel do facilitador, à qualidade do material, à participação de pessoas de vários setores e à realização de encontros presenciais acima do planejado, o que propiciou o fortalecimento de vínculos entre tutores e facilitadores. Com basenisso, os participantes sal ientaram que, em se realizando novamente o curso, é importante que se amplie o número de encontros presenciais e que estes sejam aprimorados.

Os encontros presenciais são fundamentais para fortal ecer a ação construtora da EPS a partir dos problemas identificados em cada localidade, propiciar a integração ea troca de experiência entre os facilitadores e favorecer a correspondência entre a teoria e a prática ${ }^{39}$. A pesar de se reconhecer a importância dos encontros presenciais, a valorização destes pelos participantes pode também estar relacionada às dificuldades dos sujeitos lidarem com as ferramentas do EAD e do estabelecimento da relação pedagógica, a qual se torna ainda mais complexa quando o processo deaprendizagem é desenvolvido à distância.

\section{Consideraçõesfinais}

As críticas referentes à formação de facilitadores refletiram o desafio enfrentado duranteesse processo, o qual exigiu a mobilização e o comprometimento de diversos sujeitos em um período conturbado, marcado pela greve dos profissionais de saúde. Além de refletir o desafio, as críticas também representam o desejo de fazer meIhor, de aprimorar esse processo, o qual nunca se dará por acabado, uma vez que "uma proposta pedagógica é um caminho, não é um lugar. U ma proposta pedagógica é construída no caminho, no caminhar" 24.

A pesar dos percalços, a formação defacilitadores oportunizou aos envolvidos a ampliação do olhar sobre o processo de trabalho em saúde, seja em seu local de trabalho, seja em outros níveis de atenção. Por meio do processo, os sujeitos tiveram a possibilidade de olhar para a própria prática de trabalho, comprometerem-se e sentiremse mais seguros para dar continuidade às ações deEPS. Além disso, a vivência desse processo propiciou a reflexão, a autocrítica, o crescimento pessoal e profissional e a troca de experiências.

0 fato deterem emergido críticas não significa que o curso não tenha conseguido atingir seus propósitos, uma vez que as contribuições levantadas referem-se justamente aos objetivos centrais do processo de formação de facilitadores, que é possibilitar a compreensão sobre EPS e, a partir disso, refletir sobre o processo de trabaIho. Cabe ressaltar que o curso possui a perspectiva de dinamizar um movimento, caracterizando-se como estratégia inserida no movimento pró-mudança no modelo de atenção.

O curso deveria ser um dos disparadores de uma nova prática proporcionada pelo empoderamento dos sujeitos envolvidos e pela defesa dos conceitos de EPS. As mudanças ocorridas tanto no M S como no nível gestor local limitaram o processo que se encontrava ainda pouco estruturado, dificultando com isso o desenvolvimento das funções por parte dos facilitadores.

No atual contexto, em que as discussões em torno da EPS voltam a ocupar um espaço na agenda da gestão devido à instituição da nova Portaria no $1.996 \mathrm{M} \mathrm{S/GM}{ }^{40}$, que regulamenta a política nacional de EPS, a formação de facilitadores também ganha destaque. N esse sentido, é necessário dar continuidade às discussões que 0 curso de facilitadores propunha. 0 encerramento do curso não pode interromper a construção coletiva da EPS. É necessária a criação de novas estratégias para a continuidade das práticas de EPS nos serviços de saúde, envolvendo, subsidiando e potencializando o papel do facilitador. 


\section{Colaboradores}

FF M endonça participou da elaboração do projeto, coleta e análise dos dados e redação do artigo. EFPA Nunes orientou o trabalho, participou da elaboração do projeto, auxiliou na análise dos dados e na redação do artigo. ML Garanhani e AD González atuaram na fase de construção do artigo.

\section{Referências}

1. Brasil. M inistério da Saúde. Gabinete do Ministro. Portaria no 198/GM /M S de 13 de fevereiro de 2004. Institui a Política Nacional de Educação Permanente em Saúde como estratégia do Sistema Ú nico de Saúde para formação e do desenvolvimento de trabalhadores para o setor e dá outras providências. Diário Oficial da União 2004; 16 fev.

2. Brasil. Ministério da Saúde. Secretaria de Gestão do Trabalho e da Educação na Saúde. Departamento de Gestão da Educação na Saúde. Política de Educação e desenvolvimento para o SUS: Caminhos da Educação Permanente em Saúde: Pólos de Educação permanente em Saúde. Brasília: Ministério da Saúde; 2004.

3. Brasil. M inistério da Saúde. Secretaria de Gestão do Trabalho e da Educação na Saúde. Departamento de Gestão da Educação na Saúde. EducarSUS N otas sobre o Desempenho da Gestão da Educação na Saúde. Brasília: M inistério da Saúde; 2005.

4. Ceccim RB. Educação permanente em saúde: desafio ambicioso e necessário. Interface (Botucatu) 2005; 9(16):161-177.

5. Londrina. Prefeitura Municipal de Londrina. Educação permanente em saúde das equipes de saúde da família como estratégia de mudança de prática: avaliação do processo. Londrina: Prefeitura M unicipal de Londrina; 2006.

6. Merhy EE, Feuerwerker LCM, Ceccim, RB. Educación permanente en salud - una estrategia para intervenir en la micropolítica del trabajo en salud. Salud colect 2006; 2(2):147-160.

7. M inayo MCS, Deslandes SF, Cruz Neto O, Gomes R. Pesquisa social: teoria, método e criatividade. $\mathrm{Pe}-$ trópolis: Vozes; 2000.

8. M inayo MCS. O desafio do conhecimento: pesquisa qualitativa em saúde. São Paulo: Hucitec;1996.

9. Martins J, Bicudo MAV. A pesquisa qualitativa em psicologia: fundamentos e recursos básicos. São Paulo: Centauro; 2005.

10. Feuerwerker L. Educação permanente em saúde: uma mudança de paradigmas. Olho Mágico 2005; 12(3):13-20.

11. Brasil. M inistério da Saúde. Secretaria de Gestão do Trabalho e da Educação na Saúde. Departamento de Gestão da Educação na Saúde. Conversando sobre os pólos de educação permanente em saúde. Olho Mágico 2005; 12(1):9-14.

12. Campos GWS. Saúde Paideia. São Paulo: Hucitec; 2007.

13. Goulart FAA. Pólos de educação permanente em saúde: desvios e ilusões do que poderia ter sido um boa ideia. Olho Mágico 2004; 11(4):12-14.

14. Giovanella L. Ideologia e poder no planejamento estratégico em saúde: uma discussão da abordagem de M ário Testa [dissertação]. Rio de Janeiro (RJ): Escola Nacional de Saúde Pública, Fundação Oswaldo Cruz; 1989

15. M oraes MAA, M anzani EJ. Concepções sobre a aprendizagem baseada em problemas: um estudo de caso na Fanema. Rev. bras. educ. med. 2006; 30(3):125-135.

16. Vasconcelos $C$. M etodologia dialética em sala de aula. Rev AEC 1992; 21(83):28-55. 
17. Pereira ALF. As tendências pedagógicas e a prática educativa nas ciências da saúde. Cad Saude Publica 2003; 19(5):1527-1534.

18. Freire P. Educação e mudança. Rio de Janeiro: Paz e Terra; 2001.

19. Campos GWS. U m método para análise e co-gestão de coletivos: a constituição do sujeito, a produção de valor de uso e a democracia em instituições: o método da roda. São Paulo: Hucitec; 2000.

20. Luckesi CC. Filosofia da educação. São Paulo: Cortez; 1994.

21. Torres RM, organizador. Educação popular: um encontro com Paulo Freire. São Paulo: Loyola; 2002.

22. Garanhani ML. Habitando o mundo da educação em um currículo integrado de enfermagem: um olhar à luz de H eidegger [tese]. Ribeirão Preto (SP): Universidade de São Paulo; 2004.

23. Alves L, N ova C. Educação a distância: limites e possibilidades. São Paulo: Futura; 2003.

24. Kramer S. Propostas pedagógicas ou curriculares: subsídios para uma leitura crítica. Educ. Soc. 1997; 18(60):15-35.

25. Freire P. Pedagogia da autonomia: saberes necessários à prática educativa. São Paulo: Paz e Terra; 2006.

26. Brasil. M inistério da Saúde. Secretaria de Gestão do Trabalho e da Educação na Saúde. Departamento de Gestão da Educação na Saúde. Curso de formação de facilitadores em educação permanente em saúde: orientação pra o curso. Braślia: Ministério da Saúde; 2005.

27. Anastasiou LC. Ensinar, aprender, apreender e processos de ensinagem. In: Anastasiou LC, Alvez LP, organizadores. Processos de ensinagem na universidade: pressupostos para as estratégias de trabalho em aula. Joinville: UNIVILLE; 2007. p. 15-43.

28. Cyrino EG, Toralles-Pereira M R. Trabalhando com estratégias de ensino-aprendizado por descoberta na área da saúde: a problematização e a aprendizagem baseada em problemas. Cad Saude Publica 2004; 20(3):780-788.

29. Batistta N, Batista SH, Goldenberg P, Seiffert O, Sonzogno MC. $O$ enfoque problematizador na formação de profissionais de saúde. Rev. Saude Publica 2005; 39(2):231-237.

30. Job GA. Educação permanente em saúde: um desafio para a mudança de prática do cuidado em saúde [trabalho de conclusão de curso]. Criciúma (SC): Universidade do Extremo Sul Catarinense; 2006.

31. Cotta RMM, Schott M, Azaredo CM, Franceschini SCC, Priore SE, Dias G. Organização do trabalho e perfil dos profissionais do Programa Saúde da Família: um desafio na reestruturação da atenção básica em saúde. Epidemiol. Serv. Saude 2006;15(3):7-18.

32. Brasil. Ministério da Saúde. Secretaria de Gestão do Trabalho e da Educação na Saúde. Departamento de Gestão da Educação na Saúde. Curso de facilitadores de educação permanente em saúde: unidade de aprendizagem - trabalho e relações na produção do cuidado. Brasília: M inistério da Saúde; 2005.
33. Campos GWS. Subjetividade e administração de pessoal: considerações sobre modos de gerenciar 0 trabalho em equipes de saúde. In: M erhy EE, Onocko R, organizadores. Agir em saúde: um desafio para o público. São Paulo: Hucitec; 1997. p. 229-266.

34. Merhy EE. Em busca do tempo perdido: a micropolítica do trabalho vivo em saúde. In: M erhy $E E$, Onocko R, organizadores. Agir em saúde: um desafio para o público. São Paulo: Hucitec; 1997. p. 71-150.

35. Pinheiro R. As práticas do cotidiano na relação oferta e demanda dos serviços de saúde: um campo de estudo e construção da integralidade. In: Pinheiro R, Mattos RA, organizadores. Os sentidos da integralidade: na atenção e no cuidado à saúde. Rio de Janeiro: Abrasco; 2006. p. 67-113.

36. Morin E. A cabeça bem-feita: repensar a reforma, reformar o pensamento. Rio de Janeiro: Bertrand Brasil; 2006.

37. Roschke MA. C. Educação permanente - compreensão: alguns conceitos e características essenciais. Olho M ágico 2006; 13(3):32-35.

38. Falcón GS, Erdmann AL, Meirelles BHS. A complexidade na educação dos profissionais para o cuidado em saúde. Texto Contexto Enferm 2006; 15(2):343-351.

39. Brasil. M inistério da Saúde. Secretaria de Gestão do Trabalho e da Educação na Saúde. Departamento de Gestão da Educação na Saúde. Curso de facilitadores de educação permanente em saúde: unidade de aprendizagem - Integradora. Brasília: M inistério da Saúde; 2005.

40. Brasil. M inistério da Saúde. Gabinete do M inistro. Portaria no 1.996/GM /M S de 20 de agosto de 2007. Dispõe sobre as diretrizes para a implementação da Política Nacional de Educação Permanente em Saúde e dá outras providências. Diário Oficial da União 2007; 22 ago.

Artigo apresentado em 16/12/2007

Aprovado em 27/06/2008

Versão final apresentada em 06/08/2008 